www.jmscr.igmpublication.org

Impact Factor (SJIF): 6.379

Index Copernicus Value: 79.54

ISSN (e)-2347-176x ISSN (p) 2455-0450

crossrefDOI: https://dx.doi.org/10.18535/jmscr/v6i11.32

Journal Of Medical Science And Clinical Research

\title{
Use of Intravenous Tranexamic Acid in Primary Total Knee Replacement
}

\section{Authors}

\section{Dr Piriyan T $\mathbf{P}^{1}$, Prof. Dr Senthilnathan $A^{2}$, Dr Prabhakar $\mathbf{R}^{3}$}

${ }^{1}$ Post graduate, Department of Orthopaedics, Rajah Muthiah Medical College, Chidambaram

${ }^{2}$ Professor and Unit Chief, Department of Orthopaedics, Rajah Muthiah Medical College, Chidambaram

${ }^{3}$ Lecturer, Department of Orthopaedics, Rajah Muthiah Medical College, Chidambaram

\begin{abstract}
Introduction: The use of tranexamic acid in any form (intravenous, intra articular, oral) in total knee arthroplasty surgeries has been the subject of constant study. The different strategies to reduce bleeding are aimed at reducing the need for blood transfusion due to the risks involved. In our study we established the use of tranexamic acid in reducing peri operative and post operative bleeding, the need for blood transfusion and the prevalence of developing postoperative deep vein thrombosis in patients who had undergone total knee replacement.

Materials and Methodology: 22 patients who underwent primary total knee arthroplasty from May 2016 to September 2018 were included in this study and are divided into two groups. 11 patients in one group received a single dose of $1 \mathrm{~g}$ of IV TXA (Group TXA) 10 mins before opening the pneumatic tourniquet. 11 patients in other group who didn't receive IV TXA are termed as control group (Group C). Haemoglobin, the amount of blood loss and the number of blood transfusions were recorded and taken into account 24 hours after surgery. Deep vein thrombosis occurrence in patients post operatively was evaluvated during patient's stay in the hospital and 2 weeks and 1 month after surgery in review visits. This study is not a randomized study.
\end{abstract}

Results: Group TXA had less mean haemoglobin reduction post operatively compared to Group $C(p=0.001)$. Blood loss following surgery was very much higher in Group C compared to group TXA $(p=0.001)$. The total number of blood transfusions done post operatively was higher in Group $C(p=$ 0.04). There were no occurrence of thrombo embolic events in this study.

Conclusion: Use of IV Tranexamic acid reduced postoperative bleeding without promoting thromboembolic events.

Keywords: Anaesthesia; Tranexamic acid; Total knee replacement; Bleeding; Blood transfusion.

\section{Introduction}

The idea to use tranexamic acid as a strategy to reduce blood loss in surgery of primary total knee arthroplasty has been the subject of constant study, because TKA surgery is associated with huge amounts of bleeding that can reach upto $20 \%$ to $30 \%$ of the volume in patients who already have many life threatening co morbidities related to cardiovascular, cerebrovascular and metabolic systems due to the existing epidemiological characteristics of knee arthritis/arthrosis. ${ }^{1}$ In these patients, the amount of blood loss leading to post operative anaemia promotes high morbidity and mortality. ${ }^{2}$ Patients with peri and 
post operative anaemia have prolonged hospitalization and are associated with a greater need for the use of resources including blood transfusions, blood products and ICU admissions. ${ }^{3,4-5}$

Different strategies for reducing blood loss have been used,to reduce the need for transfusion of blood and its products due to the risks associated. ${ }^{4}$ Not only the transmission of bacterial and viral diseases but the immunomodulation due to homologous transfusion has been a growing concern because of the increasing evidence in the prevalence of prostheses infections, immunosuppression. ${ }^{4,6,7-8}$

In our study, we studied to evaluate the use of intravenous tranexamic acid in reducing perioperative and postoperative bleeding, the need for transfusion of blood and blood related products and the prevalence of developing postoperative deep venous thrombosis in patients who underwent total knee arthroplasty.

\section{Methods}

In our study, we included 22 patients who underwent total knee arthroplasty due to osteoarthrosis or rheumatoid arthritis, from May 2016 to September 2018 in our hospital at the Division of orthopaedics, RMMCH, Chidambaram. This study is not a randomized study. We divided the patients into two groups. 11 patients in one group received intravenous tranexamic acid $1 \mathrm{~g}$ (Group TXA) as a single dose 5 min before the opening of the pneumatic tourniquet. 11 patients in other group a control group where patients didn't received any form of tranexamic acid (Group C). This study is not a randomized study. 11 patients in control group didn't receive IV TXA because of surgeons preference and also the patients low pre operative haemoglobin level and associated co-morbidities like hypertension and many other factors.

Anaesthetic technique used was mostly combined regional anaesthesia chosen by the anaesthesiologists. Total knee arthroplasty was performed with standard operative technique using a cemented prosthesis. A pneumatic tourniquet inflated with compressed air with pressure of $150 \mathrm{mmHg}$ above the systolic blood pressure of the patient was used.

The amount of postoperative blood loss was measured in a drainage system placed by the surgeon in the surgical wound and was recorded in the first 24 hours after surgery. Both the preoperative haemoglobin value and the postoperative haemoglobin value which was measured $24 \mathrm{hrs}$ after surgery were taken into account. The need for blood transfusion was observed in both groups at $24 \mathrm{hrs}$ postoperatively. The criteria for transfusion were done according to the protocol used by the surgeon i.e bleeding greater than $20 \%$ of blood volume or postoperative haemoglobin less than $10 \mathrm{~g} \mathrm{dL}^{-1}$.

The occurrence of postoperative deep vein thrombosis (DVT) was studied through clinical history and physical examination during the patient's hospitalisation and doppler ultrasound performed with flow analysis in the region with clinically suspected DVT. In the follow-up visit, 2 weeks and 1 month post operatively the investigation to rule out DVT was repeated by the surgeon.

Statistical analysis was performed by an experienced senior statistician. Data were analyzed with the Student's $t$-test for quantitative variables and Mannwhitney $U$ test for qualitative variables.

\section{Results}

A total of 22 patients who underwent Total knee arthroplasty were included and are divided into two groups viz 11 patients who received IV TXA (Group TXA) and 11 patients who didn't receive tranexamic acid (Group C).The mean age of group TXA was $56.95 \pm 3.60$ years and $57.90 \pm 4.06$ years for Group C. The difference is statistically insignificant $(\mathrm{z}=1.24 . \mathrm{p}=0.21)$. Therefore the two groups are homogenous with respect to age. Similarly, homogeneity was observed for gender $\left(\mathrm{x}^{2}=0.052, \mathrm{p}=0.81\right)$. 
The difference in the reduction of haemoglobin after surgery between groups was statistically significant (Table 1). As the mean difference was lesser in Group TXA, it is inferred that there was statistically significant lesser reduction in haemoglobin in patients administered with tranexamic acid.

Table- 1 Comparison of $\mathrm{Hb}$

\begin{tabular}{|l|c|c|c|c|c|}
\hline \multirow{2}{*}{ Hb $(\mathbf{g} / \mathbf{d} \mathbf{l})$} & TXA & Control & Hb reduction & \multicolumn{2}{|c|}{ 't' test } \\
\cline { 2 - 6 } & Mean & Mean & MEAN & 't' & 'p' \\
\hline Pre $\mathrm{Hb}$ & $12.34 \pm 1.52$ & $11.53 \pm 1.28$ & $1.20 \pm 0.29$ & \multirow{2}{*}{4.45} & $0.001^{*}$ \\
\hline Post $\mathrm{Hb}$ & $11.14 \pm 1.54$ & $9.42 \pm 1.09$ & $2.10 \pm 0.60$ & & \\
\hline
\end{tabular}

The amount of blood loss postoperatively was very much higher in Group $\mathrm{C}(\mathrm{z}=4.00, \mathrm{p}=0.001)$ as shown in figure 1.

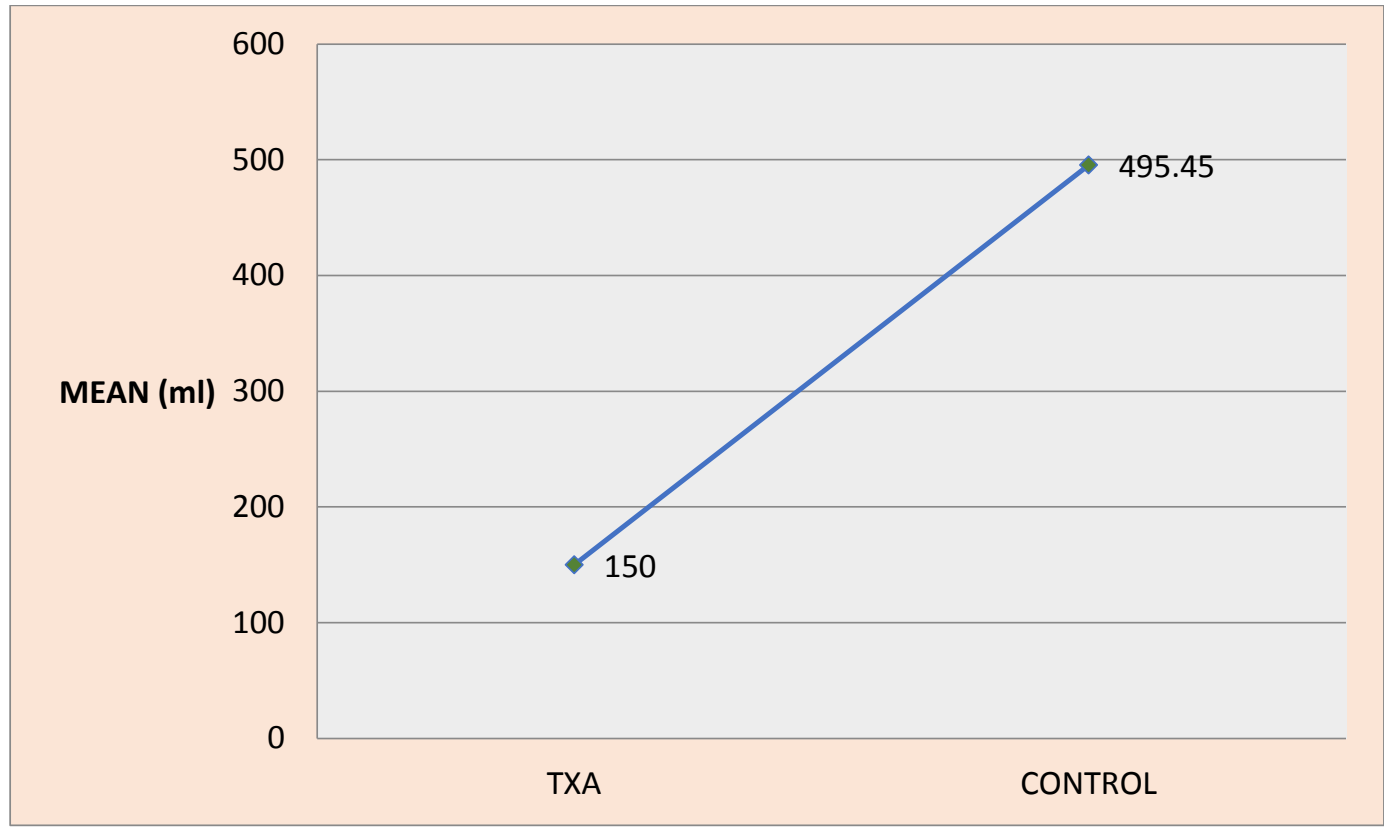

Figure 1 Blood Loss Comparison $-4^{\text {th }}$ hour

There was significant difference $(\mathrm{z}=1.89, \mathrm{p}=0.04)$ in the number of blood transfusions done between groups. The majority of Group TXA had not

Table- 2 Comparison of Blood Transfusion

\begin{tabular}{|c|c|c|c|c|c|c|}
\hline \multirow{2}{*}{$\begin{array}{l}\text { Unit of } \quad \text { Blood } \\
\text { Tranfusion }\end{array}$} & \multicolumn{2}{|c|}{ TXA } & \multicolumn{2}{|c|}{ Control } & \multicolumn{2}{|c|}{ Mannwhitney 'U' test } \\
\hline & $\mathbf{N}$ & $\%$ & $\mathbf{N}$ & $\%$ & 'z' & 'p' \\
\hline Nil & 7 & 63.6 & - & - & \multirow{5}{*}{1.89} & \multirow{5}{*}{$0.04 *$} \\
\hline 1 Unit & 4 & 36.4 & 3 & 27.3 & & \\
\hline 2 Unit & - & - & 6 & 54.5 & & \\
\hline 3 Unit & - & - & 2 & 18.2 & & \\
\hline Total & 11 & 100 & 11 & 100 & & \\
\hline
\end{tabular}

$* \mathrm{p}$ value statistically significant $(\mathrm{p}<0.05)$

The occurrence of Deep venous thrombosis was not observed in both groups.

\section{Discussion}

The present study showed a significant reduction in post operative bleeding in patients who received IV TXA because the anti fibrinolytic required blood transfusion whereas all the patients in the Group $\mathrm{C}$ were in need of blood transfusion following surgery (Table 2). 
plasminogen conversion to plasmin. Thrombin (factor 2) also activates fibrinolysis by t-PA release from the vascular endothelium. ${ }^{9}$ Surgical stress increases the release of plasmin at the site of vascular damage and it amplifies fibrinolysis.

Tranexamic acid is a synthetic inhibitor of fibrinolysis, which competitively inhibits activation of plasminogen to plasmin ${ }^{10,11}$ which results in delay of fibrinolysis due to nonplasmin formation and as a result binding to fibrinogen or to fibrin monomers does not occur and this results in a clot stabilization. ${ }^{4}$

Among many methods to reduce peri and post operative bleeding in total knee arthroplasty, one method is the use of pneumatic tourniquet during the perioperative period. ${ }^{12}$ However, this tourniquet decreases only intraoperative blood loss when inflated, but when deflated an increase in bleeding is seen, which is due to the hyperfibrinolysis which in turn is due to the plasmin release from the surgical bed. ${ }^{13,14}$

Many authors used tranexamic acid to establish its effect in reducing bleeding and the need for transfusion of blood and blood related products in primary total knee arthroplasty. However, there was no established consensus regarding the dose and the time to administer the drug in many studies. ${ }^{15,16-17}$

Orpen et al. reported a statistically significant blood loss reduction of about $45.5 \%(p=0.006)$ in the immediate postoperative period in the group receiving $15 \mathrm{mg} \mathrm{kg}^{1}$ intravenous tranexamic acid in patients who underwent cemented total knee replacement compared to the group who received saline solution at the same time. And postoperatively there was no reports of occurrence of deep vein thrombosis (DVT) in both groups. ${ }^{12}$

In another study including patients diagnosed with fracture hip treated with various surgical modalities, the IV administration of TXA $(15 \mathrm{mg}$ $\mathrm{kg}^{-1)}$ at the time of skin incision and and the dose is repeated 3 hours later (a total of $30 \mathrm{mg}$ $\mathrm{kg}^{-1)}$ reduced the need for blood transfusion. ${ }^{18}$
In studying the efficacy of antifibrinolytic, Camarasa et al used IV TXA at a dose of $10 \mathrm{mg}$ $\mathrm{kg}^{-1} 10$ mins before deflating the tourniquet, and he repeated the same 3 hours after the same IV dose and he demonstrated a decrease in blood loss in patients undergoing total knee arthroplasty. ${ }^{19}$

Recent systematic review of RCTs conducted, concluded that the use of IV TXA in TKA as a strategy in reducing perioperative and postoperative bleeding reduced the need for blood transfusions by at least $50 \%$ and also the complications that occurs with it. This signifies the use of this drug in reducing blood loss of about atleast $400 \mathrm{ml}^{20}$

In our study, we used IV TXA in equivocal dose (i.e $1 \mathrm{~g}$ ) for all patients, and is administered 10 mins before deflating the pneumatic tourniquet, and the drug is administered in rapid infusion. Many authours quoted in their studies that surgeries which require significant reduction in bleeding and also there is a physiological fibrinolysis activation advocated the use of tranexamic acid doses between 1 and $5 \mathrm{~g} .{ }^{21}$

In our study, regarding the preoperative and postoperative haemoglobin values, the loss was more in control group compared to group TXA. In our study we followed a surgical protocol in which patients who were presented with post operative $\mathrm{Hb}<10 \mathrm{~g} \mathrm{dL}^{-1}$ or post operative blood loss $>20 \%$ of their blood volume would be considered for blood transfusion.

This protocol is consistent with the "post operative blood transfusion needs' literature with regard to lessen the patient's exposure to homologous blood and blood related products transfusion. Ballantyne et al by applying a simple protocol, similar to that used in this study showed a $32 \%$ reduction in blood transfusions when adopted a transfusion criterion of $\mathrm{Hb}$ of $8.5 \mathrm{~g} \mathrm{dL}^{-1}$ compared to $\mathrm{Hb}$ of $11 \mathrm{~g} \mathrm{dL}^{-1} .^{22}$

Zadzilka et al with the same idea and purpose , proposed a method to reduce preoperative transfusion of blood and blood products for the 
establishment of a tolerable $\mathrm{Hb}$ level in order to perform the blood transfusion. ${ }^{23}$

In our study, the number of units of blood transfused was double in group C compared to group TXA. So, we claim a relationship between the need for post operative blood transfusion and the use of intravenous tranexamic acid because the result was statistically significant.

Many studies also have reported that in patients undergoing major orthopaedic surgeries, there is an increase in the incidence of thrombo embolic events when IV TXA is used. This increase in incidence of thromboembolic events is not only based on the effects of antifibrinolytic drugs but also associated with prolonged bed rest and prothrombotic activity of the inflammatory response to the surgical trauma. However, in this present study we did not use any LMWH perioperatively, but still there was no evidence of thrombo embolic events in both group of patients.

In assessing the efficacy and safety of increasing doses of intravenous tranexamic acid $(1000 \mathrm{mg}$; $2000 \mathrm{mg}$; and $3000 \mathrm{mg}$ ) in patients undergoing total knee arthroplasty, a study showed no thromboembolic events in their studied groups. ${ }^{24}$

Many such similar studies have failed to show an association between the use of IV TXA and the occurrence of thromboembolic events. ${ }^{9,13}$ The likely explanation to this lies in the fact that tranexamic acid does not affect the fibrinolytic activity on the walls of the veins and so it does not promote prothrombotic activity in their studied groups. ${ }^{13}$

\section{Conclusion}

In our study, we conclude that the use of Intravenous tranexamic acid reduces peri and postoperative bleeding in primary total knee arthroplasty, with the absence of occurrence of thromboembolic events post operatively.

\section{References}

1. Michel JWP, Schlüter-Brust KU, Eysel P. Study on epidemiology, etiology, diagnosis, and treatment of osteoarthritis of the knee. Dtsch Arztebl Int. 2010;107: 152-62.

2. Carlson JL, Duff A, Berlin JA, et al. Relationship between Perioperative blood transfusion and postoperative mortality. JAMA. 1998;279:199-205.

3. Baron DM, Hochrieser H, Posch M, et al. Study on Pre operative anaemia and its association with poor clinical outcome in non-cardiac surgery patients. Br J Anaesth. 2014;113:416-23.

4. Hynes M, Calder P, Scott G. IV tranexamic acid use to reduce blood loss during total knee arthroplasty. The Knee. 2003;10:375-7.

5. Kotzé A, Carter LA, Scally AJ. Study relating the Effect of patient blood management programme on preoperative anaemia, transfusion rate, and outcome after primary hip and knee arthroplasty: a quality improvement cycle. Br J Anaesth. 2012; 108:943-52.

6. Snyder GL, Grinberg S. Study on the Effect of anaesthetic technique and other perioperative factors on cancer recurrence. Br J Anaesth. 2010; 105: 106-15.

7. Wheatley $\mathrm{T}$, Veitch PS. Relationship between the Effect of blood transfusion and the postoperative immunecompetence. Br J Anaesth1997;78:489-92.

8. Garneti N, Field J. Bone bleeding during total hip arthro- plasty after administration of tranexamic acid. J Arth. 2004;19:48892.

9. Jansen J, Andreica S, Claeys M, et al. Use of tranexamic acid for an effective blood conservation strategy after total knee arthroplasty. Br J Anaesth. 1999; 83:596601.

10. Mac Gillivray RG, Tarabichi SB. Tranexamic acid to reduce blood loss after 
bilateral total knee arthroplasty - a prospective, randomized double blind study. J Arth. 2011;26:24-8.

11. McConnel JS, Shewale S, Munro NA, et al. Reducing blood loss in primary knee arthroplasty: a prospective randomized con- trolled trial of tranexamic acid and fibrin spray. The Knee. 2012;19:295-8.

12. Orpen NM, Little C, Walker G, et al. Tranexamic acid reduces early postoperative blood loss after total knee arthroplasty: a prospective randomised controlled trial of 29 patients. The Knee. 2006;13:106-10.

13. Benoni G, Lethagen S, Fredin H. The effect of tranexamic acid on local and plasma fibrinolysis during total knee arthroplasty. Thromb Res. 1997; 85: 195206.

14. Tarwala R, Dorr LD, Gilbert PK, et al. Tourniquet use during cementation only during total knee arthroplasty: a randomized trial. Clin OrthopRelat Res. 2014;472:169-74.

15. Charoencholvanich K, Siriwattana-sakul P. Tranexamic acid reduces blood loss and blood transfusion after TKA: a prospective randomized controlled trial. Clin OrthopRelat Res. 2011;469:2874-80.

16. Maniar RN, Kumar G, Singhi T, et al. Most effective regimen of tranexamic acid in knee arthroplasty: a prospective random- ized controlled study in 240 patients. Clin OrthopRelat Res. 2012;470:2605-12.

17. Gandhi R, Evans HMK, Mahomed SR, et al. Tranexamic acid and reduction of blood loss in total knee and hip arthroplasty: a meta-analysis. BMC Res Notes. 2013;6:184, doi: http://www.biomedcentral.com/17560500/6/184.
18. Zufferey PJ, Miquet M, Quenet S, et al. Tranexamic acid in hip fracture surgery: a randomized controlled trial. Br J Anaesth. 2010;104:23-30.

19. Camarasa MA, Ollé G, Serra- Prat M, et al. Efficacy of aminocaproic, tranexamic acid in the control of bleeding dur- ing total knee replacement: a randomized clinical trial. Br J Anaesth. 2006;96:57682.

20. Kagoma YK, Crowther MA, Douketis J, et al. Use of antifibri- nolytic therapy to reduce transfusion in patients undergoing orthopedic surgery: a systematic review of randomized trials. Thromb Res. 2009;123:687-96.

21. Mannucci PM, Levi M. Prevention and treatment of major blood loss. N Engl J Med. 2007;356:2301-11.

22. Ballantyne A, Walmstey P, Brenkel I. Reduction of blood transfusion rates in unilateral total knee arthroplasty by the introduction of a simple blood transfusion protocol. The Knee. 2003;10:379-84.

23. Zadzilka JD, Stulberg BN. Blood conservation in total kneearthroplasty: hedging your bets. Semin Arthro. 2011;22:150-2.

24. Poeran J, Rasul R, Suzuki S, et al. Tranexamic acid useand postoperative outcomes in patients undergoing totalhip or knee arthroplasty in United States: retrospective analysis of effectiveness and safety. BMJ. 2014;349:g4829, http://dx.doi.org/10.1136/bmj.g4829. 